\title{
CRESCIMENTO E DESENVOLVIMENTO DE CULTIVARES DE BANANEIRA IRRIGADAS ${ }^{1}$
}

\author{
JURACY ROCHA BRAGAFILHO ${ }^{2}$, JORGE LUIZ DO NASCIMENTO ${ }^{3}$, RONALDO VELOSO NAVES $^{4}$, \\ LUCIANA BORGES E SILVA², ARCÂNGELACUSTÓDIADACONCEIÇÃO PEDREIRAPEREIRA ${ }^{5}$, \\ HELENICE MOURA GONÇALVES ${ }^{6}$, CRISTIANE RODRIGUES ${ }^{7}$
}

RESUMO - Este estudo teve como objetivo avaliar o comportamento vegetativo de cultivares de bananeira sob lâminas de irrigação. As lâminas de irrigação corresponderam à testemunha, 40; 80 e 120\% da evapotranspiração potencial da cultura estimada a partir da evaporação do tanque classe A. O experimento foi conduzido no período de 24 de janeiro de 2004 a 23 de janeiro de 2006, com as cultivares: falsa FHIA 18, Grande Naine, Prata e Thap Maeo. As quatro cultivares apresentaram respostas significativas às lâminas de irrigação, no entanto falsa FHIA 18 teve o maior número de variáveis influenciadas. O uso da irrigação influenciou de forma diferenciada no comportamento das cultivares. O efeito de lâminas dentro de cultivares, aos quatro meses após o plantio, ocorreu apenas na cultivar Prata para a altura de plantas, aos oito meses do plantio em todas as cultivares e variáveis. Na ocasião da colheita, houve efeito das lâminas de irrigação dentro das quatro cultivares. No segundo ciclo, não se verificou resposta à irrigação aos quatro e oito meses da escolha do primeiro seguidor; ocorreu o efeito de cultivares e resposta à irrigação no número de folhas viáveis aos quatro meses dentro de Grande Naine, e na altura de plantas e no diâmetro aos oito meses. O crescimento e o desenvolvimento vegetativo das cultivares falsa FHIA 18, Grande Naine, Prata e Thap Maeo, nas condições do Cerrado, são influenciados positivamente com o uso da irrigação. O ciclo total das quatro cultivares diminui com o uso da irrigação.

Termos para indexação: Musa sp., bananeira, crescimento, desenvolvimento, irrigação.

\section{GROWTH AND DEVELOPMENT OF IRRIGATED BANANA ORCHARD CULTIVARS}

ABSTRACT - This study had the objective of evaluating the vegetative cultivars behavior of banana orchard under levels of irrigation. The irrigation levels indicated the control 40,80 and 120\% of the evaporation-transpiration potential of the culture based on evaporation in a classe- A tank. The experiment was lead in the period of January 24, 2004 through January 23, 2006, with the cultivars of: false FHIA 18, Grand Naine, Prata and Thap Maeo. The four cultivars presented significant answers to the irrigation levels, however false FHIA 18 had the biggest number of variables influenced by the irrigation levels. The use of the irrigation levels influenced the behavior of the cultivars in a differentiated manner. The effect of levels inside the cultivars, four months after the plantation, affected only the height of plants in the Prata cultivars. By eight months, every cultivars and variables were affected. At the time of harvest, the levels of irrigation had affected all the four cultivars. During the second cycle, a feedback to the irrigation levels was not observed in the four and eight months of the first follower; the effect occurred to the cultivars and the feedback to the irrigation in the number of viable leaves by four months of the cultivars Grand Naine, and in the height of plants and in the diameter by eight months. The growth and the vegetative development of the false FHIA 18, Grand Naine, Prata and Thap Maeo cultivars in the conditions of the open pasture are positively influenced with the use of the irrigation. The total cycle of the four cultivars decreases with the use of the irrigation.

Index terms: Musa sp., banana orchard, growth, development, irrigation.

\section{INTRODUÇÃO}

O Brasil é o segundo maior produtor e consumidor mundial de banana, ficando atrás apenas da Índia (Moreira, 1999). No Sul e no Sudeste, é mais cultivada a Grande Naine, pertencente ao subgrupo Cavendish, enquanto em todas as demais regiões, são preferidas cultivares tipo Prata (Silva et al., 2002).

A bananeira, por ser uma planta tipicamente tropical, encontra condições climáticas favoráveis ao seu cultivo em quase todo o Brasil, com destaque para as regiões Norte, Nordeste, Centro-Oeste, grande parte da região Sudeste e alguns microclimas do Sul. A planta necessita de calor constante, precipitações bem distribuídas e umidade elevada (Alves, 1999).

As plantas possuem crescimento contínuo durante o ano, e suas características fenológicas podem variar em função dos genótipos utilizados, apresentando maior ou menor crescimento

\footnotetext{
${ }^{1}$ (Trabalho 204-07). Recebido em: 21-08-2007. Aceito para publicação em: 08-08-208. Parte da tese de doutorado em Produção Vegetal do primeiro autor, apresentada à EA/UFG. Bolsista CNPq.

${ }^{2}$ Eng $^{\circ}$ Agr $^{\circ}$, Dr. Escola de Agronomia e Engenharia de Alimentos /UFG. Goiânia-GO. Email: juracyr@yahoo.com.br; lborges1001@yahoo.com.br

${ }^{3}$ Prof. Dr. do Setor de Engenharia Rural-EA/UFG, Caixa Postal 131, CEP 74001-970. Goiânia-GO. Email: jln@agro.ufg.br

${ }^{4}$ Prof. Dr. do Setor de Horticultura-EA/UFG, Caixa Postal 131, CEP 74001-970. Goiânia-GO. Email: ronaldo@agro.ufg.br

${ }^{5}$ Eng $^{a}$ Agra , Mestre-EA/UFG. Goiânia-GO. Email: arcangela@ pop.com.br

${ }^{6}$ Aluna de graduação, estagiária-EA/UFG. Goiânia-GO. Email: helenicemg @ hotmail.com

Eng ${ }^{\mathrm{a}}$ Agr $^{\mathrm{a}}$, Aluna Especial-EA/UFG. Goiânia-GO. Email: crissolocria@yahoo.com.br
} 
e desenvolvimento vegetativo, e influenciando nos tratos culturais, fitossanitários, no tombamento de plantas e na colheita (Gonzaga Neto et al., 1995).

Na região de Selvíria-MS, a bananeira Prata apresentou ciclo vegetativo, do plantio ao florescimento, de 251 dias (Silva et al., 2006). O florescimento de Prata-Anã ocorreu em 272 dias nas condições irrigadas, em Jaíba, no norte de Minas, e na ausência de irrigação foi de 347 dias em Visconde do Rio Branco na Zona da Mata de Minas Gerais (Pereira, 1997). No sudoeste da Bahia, a Grande Naine apresentou ciclo total de 266 dias (Donato et al., 2006), enquanto nas condições de Cerrado, Silva et al. (2004) verificaram que o ciclo total médio das cultivares Grande Naine, Prata e falsa FHIA 18, foi de, respectivamente, $361 ; 408$ e 422 dias. Grande Naine e Prata não foram influenciadas pelas diferentes lâminas de irrigação, porém falsa FHIA 18 mostrou-se responsiva, apesar de ser mais tardia.

Na bananicultura, são utilizados os métodos de irrigação localizada, por superfície e por aspersão. Além de atender às necessidades hídricas das plantas durante seu ciclo de vida ou no momento de maior demanda, a irrigação permite ampliar a exploração da planta (Oliveira et al., 2000; Alves, 1999). Normalmente, nos programas de melhoramento e difusão de cultivares, é utilizada a irrigação. Em Goiânia, segundo Silva et al. (2003), os plantios realizados nos primeiros dias do mês de janeiro apresentaram a terceira menor redução percentual na demanda total de água ao longo do ciclo e a segunda maior irrigação suplementar.

A região do Cerrado possui uma estação chuvosa e uma seca, concentrando $80 \%$ da precipitação pluviométrica na estação chuvosa, que vai de novembro a abril. Dessa forma, o padrão de distribuição pluviométrica e a distribuição heterogênea da estação seca quanto a sua intensidade e duração tornam-se problemas para as atividades agropecuárias. Porém, o uso destas áreas pode ser ampliado com a introdução da prática da irrigação (Goedert, 1989). A irrigação torna-se importante para a cultura da banana na região do Cerrado, no suprimento de água nos momentos de maior demanda, caracterizado pela fase de desenvolvimento e a partir da diferenciação floral. Assim, pela importância do uso da irrigação na bananicultura, este estudo teve como objetivo avaliar o comportamento vegetativo, ou seja, o crescimento e o desenvolvimento das cultivares falsa FHIA 18, Grande Naine, Prata e Thap Maeo sob diferentes lâminas de irrigação, em Goiânia-GO.

\section{MATERIAL E MÉTODOS}

O experimento foi realizado em área experimental da Escola de Agronomia e Engenharia de Alimentos da Universidade Federal de Goiás (EA/UFG), Goiânia-GO, situada a $16^{\circ} 36^{\prime}$ de latitude sul, $49^{\circ} 17^{\prime}$ de longitude oeste e a $730 \mathrm{~m}$ de altitude. $\mathrm{O}$ clima local, segundo classificação de Köeppen, é do tipo Aw, ou seja, quente e semi-úmido com estação seca bem definida. A precipitação média anual é de $1.575,9 \mathrm{~mm}$ e o total de insolação de 2.588,1 horas (Brasil, 1992). O solo da área foi classificado como Latossolo Vermelho distroférrico.

O delineamento experimental utilizado foi blocos completos casualizados, em parcelas subdivididas e esquema fatorial $4 \mathrm{x} 4$, com quatro repetições. $O$ fator de tratamento aplicado nas parcelas correspondeu a quatro lâminas de irrigação $\left(\mathrm{L}_{1}{ }^{-}\right.$ testemunha, $\mathrm{L}_{2}-40 \%, \mathrm{~L}_{3}-80 \%$ e $\mathrm{L}_{4}-120 \%$, expressas em porcentagem da evapotranspiração potencial da cultura - ETpc). A precipitação pluvial foi de $2.407,60 \mathrm{~mm}$, no primeiro ciclo e $3.382,60 \mathrm{~mm}$, acumulada no primeiro e segundo ciclos. No primeiro ciclo, as lâminas de água corresponderam a: $\mathrm{L}_{1}-34,00 \mathrm{~mm} ; \mathrm{L}_{2}-$ $352,04 \mathrm{~mm} ; \mathrm{L}_{3}-704,08 \mathrm{~mm}, \mathrm{e} \mathrm{L}_{4}-1.056,12 \mathrm{~mm}$. Para os dois anos, as lâminas foram de: $\mathrm{L}_{1}-51,00 \mathrm{~mm} ; \mathrm{L}_{2}-514,78 \mathrm{~mm} ; \mathrm{L}_{3}-1.029,56 \mathrm{~mm}$ e $\mathrm{L}_{4}-1.544,34 \mathrm{~mm}$. Foi aplicada, sempre que necessário, logo após a adubação de cobertura, uma pequena lâmina na testemunha.

As bananeiras falsa FHIA ${ }^{1} 18$, Grande Naine, Prata e Thap Maeo compreenderam o segundo fator de tratamento, aplicado às subparcelas. As parcelas experimentais com as lâminas de irrigação foram constituídas por três fileiras de 10 plantas cada, em espaçamento 2,5 x 1,6 m. As oito plantas centrais, duas por cultivar, constituíram as parcelas úteis.

Os dados foram submetidos à análise de variância implementada, usando-se os procedimentos ANOVA e GLM, através do aplicativo SAS (SAS, 1997). Foram ajustadas equações de regressão para as características avaliadas que apresentaram efeito da aplicação das lâminas de irrigação. A partir das equações estimadas, elaboraram-se gráficos com as respectivas curvas de resposta às lâminas e os respectivos coeficientes de regressão.

O plantio foi realizado no dia 24 de janeiro de 2004, e o período das avaliações foi de dois anos, divididos em duas fases. Na primeira fase, caracterizada pelo primeiro ciclo, foi considerado o período do plantio até o dia 11 de julho de 2005, e a segunda fase, caracterizada pelo segundo ciclo, o período do plantio até 23 de janeiro de 2006.

O preparo do solo foi realizado com grade aradora, seguido da abertura dos sulcos de plantio a cada 2,5 $\mathrm{m}$. As covas foram dispostas no sulco, no espaçamento de $1,6 \mathrm{~m}$. O solo apresentava, na camada de 0,0 a $0,2 \mathrm{~m}$, as seguintes características químicas: $\mathrm{pH}\left(\mathrm{CaCl}_{2}\right)=5,1 ; \mathrm{MO}=19 \mathrm{~g} \mathrm{dm}^{-3} ; \mathrm{P}($ Mehlich $)=1,3 \mathrm{mg} \mathrm{dm}^{-3} ; \mathrm{Al}=$ 0,0 mmolc dm$^{-3} ; \mathrm{H}+\mathrm{Al}=39$ mmolc dm$^{-3} ; \mathrm{K}=112,0 \mathrm{mg} \mathrm{dm}^{-3} ; \mathrm{Ca}=23$ mmolc dm ${ }^{-3} ; \mathrm{Mg}=5$ mmolc dm ${ }^{-3} ; \mathrm{CTC}=70$ mmolc dm$^{-3} ; \mathrm{V}(\%)=$ $44,2 \%$. A adubação de plantio foi feita com $405 \mathrm{~kg} \mathrm{ha}^{-1}$ de $\mathrm{P}_{2} \mathrm{O}_{5}$. As mudas utilizadas foram do tipo pedaço de rizoma de aproximadamente $1,2 \mathrm{~kg}$. As mudas das cultivares falsa FHIA 18, Grande Naine e Prata foram obtidas na EA/UFG, e da cultivar Thap Maeo, no Câmpus de Jataí/UFG. Estas passaram por período de viveiro de seis meses para multiplicação e uniformização. No sétimo mês após o plantio, foi realizada uma calagem aplicandose $2 \mathrm{t}_{\text {ha }} \mathrm{a}^{-1}$ de calcário dolomítico.

A adubação foi realizada seguindo as indicações das análises de solo e de folha e de acordo com as recomendações da Comissão de Fertilidade de Solos de Goiás (1988) e Borges et al. (1997). A adubação de cobertura foi realizada de forma parcelada, manualmente, na quantidade de $255,37 \mathrm{~kg} \mathrm{ha}^{-1}$ ano $^{-1}$ de N, na forma de Sulfato de amônio, $114,51 \mathrm{~kg} \mathrm{ha}^{-1} \mathrm{ano}^{-1} \mathrm{de}_{2} \mathrm{O}_{5}$, na forma de superfosfato simples, e $475,12 \mathrm{~kg} \mathrm{ha}^{-1} \mathrm{ano}^{-1} \mathrm{de} \mathrm{K}_{2} \mathrm{O}$, na forma de cloreto de potássio. Como fonte de micronutrientes, foram aplicados 19,2 $\mathrm{kg} \mathrm{ha}^{-1}$ de FTE, 20,59 $\mathrm{kg} \mathrm{ha}^{-1} \mathrm{de}$ zinco na forma de sulfato de zinco e $15,87 \mathrm{~kg} \mathrm{ha}^{-1}$ de boro, na forma de 
ácido bórico. Os tratos culturais foram realizados de acordo com as recomendações de Alves (1999) e Borges et al. (1997).

O sistema de irrigação utilizado foi o de aspersão subcopa, com o uso de aspersores Naan 427 - AG (bocal com 3 mm de diâmetro). Em cada parcela, foram utilizados quatro aspersores, localizados na lateral da parcela, paralelo à fileira da cultura no espaçamento de $8,5 \mathrm{~m}$, regulados em forma de setor com ângulo de $180^{\circ}$, cobrindo toda a parcela. A necessidade hídrica da cultura (ETpc) foi estimada a partir da evaporação no tanque classe A, localizado acerca de $500 \mathrm{~m}$ do experimento. Para correção, foram utilizados os coeficientes da cultura (kc) (Doorenbos \& Pruitt, 1977) e do tanque (kt) (Doorenbos \& Kassam, 1994), realizando as irrigações de forma suplementar ao regime pluvial. Para a caracterização físico-hídrica do solo, foram consideradas as camadas de 0,0-0,2 m e 0,2-0,4 m, realizando-se a determinação da densidade do solo, conforme a metodologia recomendada pela Embrapa (1997). As curvas de retenção de água no solo foram determinadas pelo método da centrífuga, conforme descrito por Freitas Júnior \& Silva (1984), nas tensões de água correspondentes a $6 ; 8 ; 10 ; 33 ; 60 ; 100$ e $1.500 \mathrm{kPa}$ (Embrapa, 1997), e o ajuste da curva foi realizado de acordo com a metodologia proposta por Van Genuchten (1980), utilizando o software SWRC (Dourado Neto et al., 2000).

As umidades volumétricas na capacidade de campo $\left(\theta_{\mathrm{C}}\right)$ e ponto de murcha permanente $\left(\theta_{\mathrm{PMP}}\right)$ foram obtidas empregandose as curvas de retenção de água no solo, para as tensões de 6 e $1.500 \mathrm{kPa}$, respectivamente. Na camada de $0-0,2 \mathrm{~m}, \theta_{\mathrm{C}}$ e $\theta_{\mathrm{PMP}}$ foram, respectivamente, $0,3487 \mathrm{~m}^{3} \mathrm{~m}^{-3}$ e $0,2551 \mathrm{~m}^{3} \mathrm{~m}^{-3}$, e na camada de $0,2-0,4 \mathrm{~m}$ foram $0,3526 \mathrm{~m}^{3} \mathrm{~m}^{-3}$ e $0,2773 \mathrm{~m}^{3} \mathrm{~m}^{-3}$. Dessa forma, a capacidade de armazenamento de água na camada de $0-0,2 \mathrm{~m}$ foi de $18,7 \mathrm{~mm}$ e na camada de $0,2-0,4 \mathrm{~m}$ foi de $15,1 \mathrm{~mm}$, totalizando até a profundidade de $0,4 \mathrm{~m} 33,8 \mathrm{~mm}$. As irrigações eram realizadas quando a evapotranspiração estimada atingia um terço da capacidade de armazenamento de água no solo. O tempo de cada irrigação foi determinado pela evapotranspiração estimada, dividida pela intensidade de aplicação determinada em teste no campo.

No primeiro ciclo, foram realizadas avaliações nas plantas, das variáveis: altura de plantas (m), diâmetro do pseudocaule a $0,30 \mathrm{~m}$ do solo $(\mathrm{cm})$ e número de folhas viáveis, considerando-se as folhas com um mínimo de $50 \%$ de área verde. Essas avaliações foram realizadas em três períodos, aos quatro e oito meses após o plantio, e na ocasião da colheita. Nesta última, foi acrescida a leitura do diâmetro do pseudocaule na inserção do cacho $(\mathrm{cm})$. Foram avaliados: o ciclo vegetativo (em dias, do plantio ao florescimento), o número de dias do plantio até a retirada do coração, o ciclo total (em dias, entre o plantio e a colheita), o ciclo produtivo (em dias, da floração à colheita) e a escolha do primeiro seguidor (planta-filha). Do segundo ciclo, foram determinados: a altura de plantas (m), o diâmetro do pseudocaule a $0,30 \mathrm{~m}$ do solo $(\mathrm{cm})$ e o número de folhas viáveis, aos quatro e oito meses após a escolha do rebento das plantas do primeiro ciclo, denominada planta-filha ou primeiro seguidor. Foram determinados o ciclo vegetativo e número de dias para a escolha do segundo seguidor (terceiro ciclo ou planta-neta).

\section{RESULTADOS E DISCUSSÃO}

Primeiro ciclo - Na avaliação aos quatro meses após o plantio, não se verificou efeito significativo das lâminas de irrigação para nenhuma das variáveis (Tabela 1). Este comportamento deve-se ao fato de que o período do plantio até os quatro meses coincidiu com a época chuvosa (janeiro a maio) com precipitação suficiente para atender à demanda de água da cultura. Silva et al. (2004), na mesma região, porém em época diferente (maio a setembro), verificaram efeito de lâminas de irrigação sobre a altura de plantas na cultivar falsa FHIA 18, aos quatro meses após o plantio.

Analisando o efeito de lâminas de irrigação dentro de cultivares, verificou-se efeito significativo na altura de plantas, apenas na cultivar Prata, não ocorrendo relação funcional entre lâminas de irrigação e esta variável. Ocorreu efeito significativo de cultivares sobre as variáveis, diâmetro do pseudocaule a 0,30 $\mathrm{m}$ do solo (D30) e no número de folhas viáveis (NFV), após os quatro meses do plantio, o que pode ser devido a características próprias das cultivares, que apresentam taxas de crescimento distintas entre si (Tabela 1).

Aos oito meses após o plantio, verificou-se efeito das lâminas de irrigação, ao nível de $1 \%$ de probabilidade, sobre todas as variáveis avaliadas (Tabela 1 ). O período dos quatro aos oito meses após o plantio (junho a setembro) coincidiu com o período seco da região, com baixa precipitação pluvial de 7,6 mm (Figura 1). Assim sendo, a irrigação foi a responsável pelo suprimento de água para a cultura nesse período. $\mathrm{O}$ efeito de lâminas de irrigação foi verificado dentro de todas as cultivares para todas as variáveis, aos oito meses após o plantio (Tabela 1). A resposta às lâminas de irrigação foi linear para todas as variáveis, exceto para NFV na cultivar Thap Maeo, que apresentou relação funcional quadrática (Figura 2). Silva et al. (2004) verificaram, aos oito meses, resposta às lâminas de irrigação na altura de plantas e diâmetro dos pseudocaules a $0,30 \mathrm{~m}$ do solo apenas na cultivar falsa FHIA 18. No presente trabalho, foi observado, aos oito meses, o efeito de cultivares para todas as variáveis, evidenciando o crescimento diferenciado entre elas, devido às suas próprias características.

$\mathrm{Na}$ ocasião da colheita do primeiro ciclo, houve efeito das lâminas de irrigação, sobre as variáveis altura de plantas (APL), D30, diâmetro do pseudocaule na inserção do cacho (DIC) e ciclo $\left(\mathrm{CV}_{\mathrm{e}}\right)$, com significância ao nível de $1 \%$ de probabilidade, para os diâmetros a $0,30 \mathrm{~m}$ do solo e na inserção do cacho, a 5\% de probabilidade, para altura de plantas e ciclo vegetativo (Tabela 2).

Verificou-se o efeito de lâminas de irrigação dentro de todas as cultivares. Na cultivar falsa FHIA 18, a mais responsiva, as variáveis: altura de plantas, diâmetro do pseudocaule a $0,30 \mathrm{~m}$ do solo, ciclo vegetativo, número de dias para a retirada do coração (DCO) e ciclo produtivo $(\mathrm{CP})$ apresentaram resposta quadrática. O ciclo vegetativo e o número de dias para a retirada do coração da cultivar falsa FHIA 18 apresentaram comportamento semelhante (Figura 3), porém inverso ao comportamento do ciclo produtivo (Figura 4). Para as variáveis ciclo total $(\mathrm{CT})$ e escolha do primeiro seguidor ou planta-filha 
(PF), não foi possível, porém, estabelecer relação funcional para essas variáveis em função das lâminas de irrigação, devido à regressão não ter-se mostrado significativa, não se ajustando aos modelos linear ou quadrático.

Silva et al. (2004), em Goiânia-GO, verificaram, na ocasião da colheita, crescimento linear do número de folhas vivas da cultivar falsa FHIA 18 com o aumento das lâminas de irrigação. Essa influência também foi observada no diâmetro dos pseudocaules a $0,30 \mathrm{~m}$ do solo, porém houve comportamento inverso no diâmetro da inserção do cacho. Silva et al. (2002) observaram que a média do diâmetro do pseudocaule aumentou de forma contínua até o quarto ciclo produtivo, apesar da redução na taxa de crescimento a partir do terceiro ciclo. Prata e falsa FHIA 18 estavam entre as maiores médias para a variável e juntamente com Thap Maeo se elevaram continuamente. Para Alves (1999), o diâmetro do pseudocaule está relacionado ao vigor da planta e reflete a capacidade de sustentação do cacho.

A cultivar Grande Naine apresentou resposta linear para a altura de plantas e no diâmetro do pseudocaule a $0,30 \mathrm{~m}$ do solo, e quadrática para o diâmetro do pseudocaule na inserção do cacho. Houve, na ocasião da colheita, efeito de cultivares para todas as variáveis, exceto para o CT, evidenciando as características fenológicas próprias de cada cultivar.

Os valores médios de D30 em Grande Naine mostram a influência da irrigação nesta variável, apresentando-se superior a $22 \mathrm{~cm}$ a partir da lâmina 3. Silva et al. (2002) verificaram que o diâmetro médio do pseudocaule, por ocasião da colheita da cultivar Grande Naine, foi de $19,4 \mathrm{~cm}$ no primeiro ciclo. A variável não apresentou variação durante os quatro ciclos avaliados, com média, no final do período, de $20,2 \mathrm{~cm}$.

A cultivar Prata apresentou resposta linear na altura de plantas. No entanto, em Prata, verificou-se também, juntamente com Thap Maeo, o efeito de lâminas de irrigação no número de dias para a escolha do primeiro seguidor, porém sem apresentar relação funcional para essa variável, da mesma forma que na cultivar falsa FHIA 18 para esta variável. A maior responsividade de falsa FHIA 18 à aplicação de lâminas de irrigação, em detrimento de Grande Naine e Prata, corroboram as observações de Silva et al. (2004).

Os valores médios obtidos para as variáveis ciclo total, ciclo vegetativo e ciclo produtivo, das quatro cultivares, mostram que as cultivares Grande Naine, Prata e Thap Maeo apresentaram ciclo total médio de 475 dias, e a falsa FHIA 18, ciclo de 456 dias. O comportamento apresentado pelas cultivares no ciclo total foi pouco influenciado, pois, apesar de mais baixo, houve pequena diferença para as demais cultivares. As cultivares falsa FHIA 18, Grande Naine, Prata e Thap Maeo apresentaram ciclo vegetativo de 297; 344; 319 e 352 dias, e ciclo produtivo de 157; 132; 155 e 121 dias, respectivamente. A falsa FHIA 18 mostrou-se mais precoce no ciclo vegetativo, no entanto apresentou o maior ciclo produtivo. A cultivar Thap Maeo, que se mostrou semelhante à Grande Naine e à Prata no ciclo total, sendo a mais tardia no ciclo vegetativo, destacou-se na formação do cacho, no enchimento dos frutos e apresentou o menor ciclo produtivo.

No geral, a resposta às lâminas de irrigação foi semelhante nas diferentes fases de avaliação para as variáveis estudadas, com exceção do número de folhas viáveis por ocasião da colheita. No entanto, os ciclos encontrados foram superiores quando comparados com Silva et al. (2004). As características próprias de cada região concorrem para o aumento ou redução do ciclo total da cultura. Silva et al. (2006) encontraram, na região de Selvíria-MS, ciclo total da bananeira Nanica de 333 dias, e das cultivares Prata e Mysore, de 396 dias. Os ciclos vegetativos foram de 206; 251 e 263 dias para Nanica, Prata e Mysore, respectivamente. Silva et al. (2002) observaram no Recôncavo Baiano o ciclo, do plantio à colheita, de 337 dias para falsa FHIA 18, para Grande Naine e Thap Maeo, 391 dias, e para Prata, 393 dias durante o primeiro ciclo. A falsa FHIA 18 mostrou-se mais precoce no primeiro ciclo e apresentou bom desempenho para a variável nos três ciclos seguintes.

A cultivar falsa FHIA 18 mostrou-se mais precoce, no entanto seu ciclo total foi maior que o encontrado por Silva et al. (2004), de 422 dias, na mesma região. Apesar de menor comparado a este, apresentou comportamento linear em razão das lâminas de irrigação e foi considerada a mais tardia. Provavelmente, uma das possíveis causas para o comportamento da falsa FHIA 18, Grande Naine e Prata seja a época em que foi realizado o plantio, neste caso, no final do mês de janeiro. Silva et al. (2003), tomandose como referência a estimativa de demanda de irrigação suplementar, sugeriram o dia primeiro de setembro como a melhor época de plantio para a cultura da bananeira na região de Goiânia. O plantio nesta época implica menor demanda suplementar de água para a cultura.

As temperaturas mínimas recomendadas para a cultura são de $15^{\circ} \mathrm{C}$ (Moreira, 1987). Dessa forma, as plantas podem ter tido o seu desenvolvimento limitado pela baixa temperatura, não respondendo à água de irrigação; pois, de acordo com os dados meteorológicos para o período de janeiro a agosto de 2004, foram verificadas temperaturas mínimas médias abaixo do recomendado. $\mathrm{Na}$ segunda quinzena de fevereiro e primeira quinzena de março de 2004, registraram-se valores mínimos de temperatura abaixo de $15^{\circ} \mathrm{C}$. Os meses de junho, julho e agosto de 2004 apresentaram temperaturas mínimas médias de $11,2{ }^{\circ} \mathrm{C} ; 10,9{ }^{\circ} \mathrm{C}$ e $10,9{ }^{\circ} \mathrm{C}$, respectivamente. As baixas temperaturas, coincidindo com a fase de estabelecimento da cultura (janeiro a março), podem ter comprometido o desenvolvimento das plantas.

As temperaturas, nesta época, são inferiores também às encontradas no período sugerido por Silva et al. (2003), que estariam associadas também ao início da época chuvosa, não necessitando da irrigação suplementar para o estabelecimento da cultura.

Nas condições de Guanambi-BA, utilizando-se da irrigação por aspersão subcopa, as cultivares falsa FHIA 18 e Grande Naine apresentaram número de dias, do plantio à colheita do primeiro ciclo, de 360 e 340 dias, respectivamente (Donato et al., 2003). Por outro lado, no ecossistema de Mata Atlântica, nas condições de sequeiro, o número de dias do plantio à colheita do primeiro ciclo foi de 423 dias para Grande Naine, 456 dias para Prata e 476 dias para Thap Maeo (Leite et al., 2003). Verificou-se um prolongamento do ciclo total neste caso, com a ausência da irrigação.

Verificou-se alta visitação de abelhas irapuá (Trigona 
spinipes - Hymenoptera, Apidae) nos cachos da cultivar falsa FHIA 18 durante a queda das brácteas, estendendo-se por maior período em relação às outras cultivares após a retirada do coração. Isso sugere maior preferência das abelhas por essa cultivar, provocando maiores injúrias na casca. $\mathrm{O}$ ataque de abelhas às flores e frutos jovens ocorre para a retirada de resina utilizada na confecção de seus ninhos e provoca danos nos frutos. A redução de seus danos pode ser obtida a partir da retirada do coração (Fancelli, 2000). A resposta quadrática verificada para o número de dias do plantio até a retirada do coração, com tendência de redução em razão do acréscimo das lâminas, mostra que, na $\mathrm{L}_{4}$, foi encontrado o menor número médio de dias do florescimento até a retirada do coração, isto é, 25 dias após. Desse modo, o menor número de dias, do florescimento até a retirada do coração, torna-se importante para a qualidade de frutos da cultivar falsa FHIA 18 pela redução dos restos florais.

Segundo ciclo - Durante o segundo ciclo, foram feitas duas avaliações do crescimento e desenvolvimento das cultivares. $\mathrm{Na}$ avaliação aos quatro meses após a escolha da planta-filha, não se verificou efeito significativo das lâminas de irrigação para nenhuma das variáveis (Tabela 1). Esse comportamento deve-se ao fato de que o período da escolha da planta-filha até a avaliação, equivalente aos quatro meses, coincidiu com a época chuvosa (outubro a janeiro), com precipitação de $824,9 \mathrm{~mm}$, que resultou na tendência de redução do uso da irrigação no mês de outubro e sem irrigação nos meses de dezembro de 2004 e janeiro de 2005.

Analisando o efeito de lâminas de irrigação dentro de cultivares, verificou-se o efeito significativo apenas na cultivar Grande Naine para número de folhas viáveis (NFV). A variável decresceu linearmente com a aplicação de lâminas de irrigação. O efeito de cultivares foi verificado sobre todas as variáveis, apresentando alta significância.

Ao contrário do primeiro ciclo, aos oito meses da escolha da planta-filha, não foi verificado efeito das lâminas de irrigação em nenhuma das variáveis. Por outro lado, o efeito de lâminas de irrigação foi verificado, dentro de duas cultivares, nessa avaliação. A resposta às lâminas de irrigação foi linear para altura de plantas (APL) e diâmetro do pseudocaule a $0,30 \mathrm{~m}$ do solo (D30) na cultivar Grande Naine, e para o número de folhas viáveis da cultivar Prata. No entanto, para o D30, o comportamento foi decrescente. O período dos quatro aos oito meses após a escolha da planta-filha (fevereiro a maio), ainda na época chuvosa e início do período seco, apresentou precipitação pluvial de $666,6 \mathrm{~mm}$ e baixo uso da irrigação. Nesta avaliação, foi verificado o efeito de cultivares sobre todas as variáveis, também com alta significância, o que expressa as características fenológicas, próprias de cada cultivar.

Até o final do período de avaliação, não se verificou resposta às lâminas de irrigação na escolha do segundo seguidor (planta-neta) e no número de dias para o florescimento das plantas do segundo ciclo (planta-filha) ocorrido até dois anos de condução do experimento. Para a primeira variável, verificou-se, no primeiro ciclo, a influência das lâminas dentro das cultivares falsa FHIA 18, Prata e Thap Maeo, porém não houve ajuste para nenhum modelo. $\mathrm{O}$ número de dias para o florescimento, no primeiro ciclo, apresentou resposta às lâminas, e dentro de cultivares, somente em falsa FHIA 18, com comportamento quadrático.

TABELA 1- Análise de variância e teste F da altura de plantas (APL), do diâmetro do pseudocaule a 0,30 m do solo (D30) e do número de folhas viáveis (NFV) das quatro cultivares de bananeira submetidas a quatro lâminas de irrigação, aos quatro e oito meses após o plantio, no primeiro ciclo vegetativo, e aos quatro e oito meses após a escolha do primeiro seguidor, que caracterizou o início do segundo ciclo vegetativo. Goiânia-GO. 2006.

\begin{tabular}{|c|c|c|c|c|c|c|c|c|c|c|c|c|c|c|}
\hline \multirow{4}{*}{ F. variaçãa ${ }^{1}$} & \multicolumn{14}{|c|}{ QM } \\
\hline & \multirow{3}{*}{ GL } & \multicolumn{6}{|c|}{$1^{\circ}$ ciclo } & \multicolumn{7}{|c|}{$2^{\circ}$ ciclo } \\
\hline & & APL & D30 & NFV & $\mathrm{APL}$ & D30 & NFV & \multirow{2}{*}{ GL } & APL & D30 & NFV & APL & D30 & NFV \\
\hline & & & 4 meses & & & 8 meses & & & & 4 meses & & \multicolumn{3}{|c|}{8 meses } \\
\hline Blocos & 3 & $1,0357^{\mathrm{ns}}$ & $9,1908^{\text {15 }}$ & $20,5906 * *$ & $0,6311^{\text {ns }}$ & $30,1820^{15}$ & $11,6327^{15}$ & 3 & $0,5846^{\mathrm{ns}}$ & $26,8617^{15 \mathrm{~s}}$ & $0,5414^{15}$ & $1,0966^{\mathrm{nS}}$ & $56,1327^{15}$ & $10,7528^{\text {nts }}$ \\
\hline Lâminas (Li) ${ }^{2}$ & 3 & $0,7942^{\mathrm{ns}}$ & $0,7539^{\text {ns }}$ & $0,1873^{\text {ns }}$ & $2,6611^{* *}$ & $170,8733 * *$ & $140,1414 * *$ & 3 & $0,5019^{\text {ns }}$ & $16,0290^{\text {ns }}$ & $1,6212^{\mathrm{ns}}$ & $0,5172^{1 \mathrm{~s}}$ & $49,6484^{15}$ & $6,2122^{\text {ns }}$ \\
\hline Resíduo a & 9 & 0,9873 & 0,8270 & 3,4049 & 0,4241 & 25,8025 & 5,6050 & 9 & 0,3440 & 24,9736 & 4,4851 & 0,4104 & 36,2423 & 4,8230 \\
\hline Cultivares (c) & 3 & $2,0331^{\text {15 }}$ & $5,7197^{*}$ & $17,4205^{* *}$ & $3,8143^{* *}$ & $34,4025 * *$ & 27,9940 ** & 3 & $9,5367^{* *}$ & $259,6970 * *$ & $39,9805 * *$ & $25,1534 * *$ & $317,3952 * *$ & $32,7930^{* * *}$ \\
\hline Lixc & 9 & $0,8554^{\text {ns }}$ & $2,2119^{\text {ns }}$ & $1,3107^{75}$ & $0,1845^{*}$ & $4,0667^{1 \mathrm{~s}}$ & $3,0005^{\text {ns }}$ & 9 & $0,3822^{\text {ns }}$ & $31,5490^{*}$ & $3,6864^{\text {ns }}$ & $0,3722^{15}$ & $26,8690^{\mathrm{ns}}$ & $7,7165^{*}$ \\
\hline Resíduo b & 96 & 0,8676 & 2,0700 & 2,6882 & 0,0872 & 6,0015 & 3,8520 & 88 & 0,1972 & 16,0343 & 1,9672 & 0,2197 & 20,9857 & 3,2813 \\
\hline $\mathrm{Li} / \mathrm{c}$ & 12 & - & - & - & - & - & - & 12 & - & - & - & - & - & - \\
\hline Li /f. FHIA $18^{3}$ & 3 & $0,0567^{1 \mathrm{TS}}$ & $2,6316^{15}$ & $1,5895^{1 \mathrm{IS}}$ & $0,7796^{* *}$ & $48,3092 * *$ & $26,3949 * *$ & 3 & $0,4095^{\mathrm{ns}}$ & $22,0117^{\text {15 }}$ & $2,3973^{\text {ns }}$ & $0,2795^{\text {ns }}$ & $6,1963^{\text {ns }}$ & $3,2682^{15}$ \\
\hline Re. Linear $^{4}$ & 1 & - & - & & $2,0211^{* *}$ & $144,1449 * *$ & $68,8195 * *$ & 1 & - & - & - & - & - & - \\
\hline Re. Quadrática ${ }^{5}$ & . & . & - & - & - & 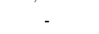 & - & . & . & . & . & . & . & . \\
\hline Desvios & 1 & & 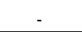 & - & $0,3040^{\mathrm{ns}}$ & $0,1159^{\text {ns }}$ & $8,5755^{7 \mathrm{~s}}$ & 1 & - & - & - & - & - & - \\
\hline Li / G. Naine ${ }^{6}$ & 3 & $0,0081^{15}$ & $1,4264^{15}$ & $0,9802^{15}$ & $0,4056^{* *}$ & $28,5820 * *$ & $20,6957 * *$ & 3 & $0,4318^{15}$ & $30,8436^{\text {15 }}$ & $5,4613^{*}$ & $0,7682 *$ & $71,0393^{*}$ & $2,9626^{\text {15 }}$ \\
\hline Re. Linear ${ }^{4}$ & 1 & - & - & - & $1,2145^{*}$ & $84,5198 *$ & $48,3969 \% *$ & 1 & - & - & $14,4588^{*}$ & $1,6359^{*}$ & $152,8056^{*}$ & - \\
\hline Re. quadrática ${ }^{5}$ & - & - & - & - & - & - & - & - & . & . & - & - & - & - \\
\hline Desvios & 1 & - & - & - & $0,0020^{15}$ & $1,1662^{\mathrm{ns}}$ & $6,3950^{\mathrm{ns}}$ & 1 & - & - & $0,2294^{\text {ns }}$ & $0,2586^{1 \mathrm{~s}}$ & $27,3430^{1 \mathrm{~s}}$ & - \\
\hline Li / Prata & 3 & $3,2705 *$ & $2,8116^{1 \mathrm{1S}}$ & $1,1618^{\text {nis }}$ & $1,4145 * *$ & $59,0036 * *$ & $61,3066 *$ * & 3 & $0,2451^{1 \mathrm{~s}}$ & $35,3622^{15}$ & $0,2413^{15}$ & $0,2501^{155}$ & $30,4259^{\text {ns }}$ & $18,6704 * *$ \\
\hline Re. Linear ${ }^{4}$ & 1 & 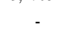 & 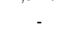 & 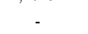 & $3,2217^{* *}$ & $157,4689 * *$ & $166,5577^{* * *}$ & 1 & 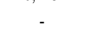 & 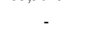 & 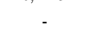 & 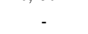 & - & 40,1321 ** \\
\hline Re. quadrática ${ }^{5}$ & - & . & - & - & - & - & - & . & . & . & - & . & - & - \\
\hline Desvios & 1 & - & - & - & $0,4634^{15}$ & $5,7883^{15}$ & $0,7357^{\mathrm{ns}}$ & 1 & - & - & - & - & - & $9,4099^{\mathrm{ns}}$ \\
\hline Li / Thap Maeo & 3 & $0,0092^{115}$ & $0,4307^{155}$ & $0,3829^{1 \mathrm{as}}$ & $0,5741^{* *}$ & $45,8034 * *$ & $38,8843 * *$ & 3 & $0,4729^{15}$ & $17,0168^{\text {15 }}$ & $4,4127^{\text {15 }}$ & $0,1594^{155}$ & $9,3300^{\text {15 }}$ & $5,1208^{\mathrm{nis}}$ \\
\hline Re. Linear $^{4}$ & 1 & - & - & - & $1,2842^{*}$ & $124,2326 *$ & - & 1 & - & - & - & - & - & - \\
\hline Re. quadrática ${ }^{5}$ & - & . & . & . & - & - & $17,7546^{*}$ & - & . & . & . & . & . & - \\
\hline Desvios & 1 & . & - & . & $0,0753^{\text {ns }}$ & $2,7620^{\text {ns }}$ & $0,1055^{\mathrm{ns}}$ & 1 & . & . & . & . & . & . \\
\hline Resíduo c(a+b) & 105 & - & - & - & - & - & - & 97 & - & - & - & - & - & - \\
\hline $\mathrm{CV}^{7}(\%)$ & - & 90,84 & 15,27 & 12,80 & 16,26 & 16,71 & 16,34 & - & 16,76 & 23,35 & 13,73 & 13,47 & 18,59 & 18,78 \\
\hline
\end{tabular}

*e**: valores significativos a 5\% e $1 \%$ de probabilidade, respectivamente; ns: não-significativo. ${ }^{1}$ Fonte de variação; ${ }^{2}$ Lâminas de irrigação (Li); ${ }^{3}$ falsa FHIA $18 ;{ }^{4}$ Regressão linear; ${ }^{5}$ Regressão quadrática; ${ }^{6}$ Grande Naine; ${ }^{7}$ Coeficiente de variação. 
TABELA 2 -Análise de variância e teste F da altura de plantas (APL), do diâmetro do pseudocaule a 0,30 m do solo (D30), do diâmetro do pseudocaule na inserção do cacho (DIC), do número de folhas viáveis (NFV), do ciclo vegetativo $\left(\mathrm{CV}_{\mathrm{e}}\right)$, do número de dias para retirada do coração (DCO), do número de dias para a colheita (CT), do ciclo produtivo (CP) e escolha do primeiro seguidor $(\mathrm{PF})$ das quatro cultivares de bananeira submetidas a quatro lâminas de irrigação, na ocasião da colheita do primeiro ciclo de produção. Goiânia-GO. 2006.

\begin{tabular}{|c|c|c|c|c|c|c|c|c|c|c|}
\hline \multirow{2}{*}{ Fonte de variação } & \multirow{2}{*}{ GL } & \multicolumn{8}{|c|}{ QM } & \multirow[b]{2}{*}{ PF } \\
\hline & & APL & D30 & DIC & NFV & $\mathrm{CV}_{\mathrm{e}}$ & DCO & $\mathrm{CT}$ & $\mathrm{CP}$ & \\
\hline Blocos & 3 & $0,0979^{\mathrm{ns}}$ & $4,1114^{\mathrm{ns}}$ & $2,0556^{\mathrm{ns}}$ & $16,2188^{\mathrm{ns}}$ & $1601,2015^{\mathrm{ns}}$ & $1998,6671^{\text {ns }}$ & $1351,8460^{\text {ns }}$ & $2513,2519^{*}$ & $992,8518^{\text {ns }}$ \\
\hline Lâminas de irrigação & 3 & $0,4694 *$ & $110,2176 * *$ & $12,7523 * *$ & $7,0128^{\mathrm{ns}}$ & $5350,1017 *$ & $4505,0697^{\text {ns }}$ & $2885,6612^{\text {ns }}$ & $368,8943^{\text {ns }}$ & $19955,2804^{\text {ns }}$ \\
\hline $\begin{array}{l}\text { Resíduo a } \\
\text { la }\end{array}$ & 9 & 0,0883 & 15,1549 & 0,6358 & 7,8922 & 1237,8884 & 1464,9036 & 2599,4870 & 441,1679 & 8778,6479 \\
\hline Cultivares (c) & 3 & $8,2770^{* * *}$ & $87,0918 * *$ & $42,2721^{* * *}$ & $46,0800^{* * *}$ & $17171,6404 * *$ & $10900,7243^{* * *}$ & $2663,3656^{\mathrm{ns}}$ & $8475,1341^{* * *}$ & $10785,7874 * *$ \\
\hline $\operatorname{Li} \times c$ & 9 & $0,2082^{\text {ns }}$ & $28,7030^{\mathrm{ns}}$ & $5,1936^{* * *}$ & $7,1923^{\text {ns }}$ & $3358,1740 * *$ & $1842,3367^{\mathrm{ns}}$ & $2006,4016^{\mathrm{ns}}$ & $592,1567^{\mathrm{ns}}$ & $2623,3249 * *$ \\
\hline Resíduo b & 90 & 0,1060 & 21,6023 & 1,6361 & 5,5124 & 1293,6014 & 1079,4609 & 1282,7476 & 326,1414 & 1248,6801 \\
\hline $\mathrm{Li} / \mathrm{c}$ & 12 & & & & & & & & & \\
\hline $\mathrm{Li} /$ falsa FHIA 18 & 3 & $0,2902^{*}$ & $36,6848^{\mathrm{nis}}$ & 5,9191 ** & $12,5401^{n-15}$ & $7599,5741 * *$ & $4930,9499^{* \cdots}$ & $5246,5865^{\cdots \cdots}$ & $943,8645 *$ & $4544,7263^{*}$ \\
\hline Regressão linear & - & - & - & - & - & - & - & $5853,7060^{\mathrm{ns}}$ & - & $1265,2352^{\mathrm{ns}}$ \\
\hline Regressão quadrática & 1 & $0,6348 *$ & - & $10,2975 * *$ & - & $13066,1069 * *$ & $7684,9635^{*}$ & $6719,4060^{\mathrm{ns}}$ & $1645,7222 *$ & $12278,7804^{\text {ns }}$ \\
\hline Desvios & 1 & $0,1424^{\text {ns }}$ & & $2,9229^{\text {ns }}$ & & $5800,0656 *$ & $2670,1365^{\text {ns }}$ & $3166,8880^{\text {ns }}$ & $475,1414^{\text {ns }}$ & $89,9844^{\text {ns }}$ \\
\hline $\mathrm{Li} /$ Grande Naine & 3 & $0,4503 * \cdots$ & $129,7757 * \cdots$ & $17,5884 * \cdots$ & $4,0105^{n-5}$ & $2924,8769^{\mathrm{ns}}$ & $1105,6457^{\mathrm{ns}}$ & $1355,8106^{\mathrm{ns}}$ & $430,7421^{n s}$ & $1847,1824^{\mathrm{ns}}$ \\
\hline Regressão linear & 1 & $0,7143 * *$ & $388,5096 * *$ & - & - & - & - & - & - & - \\
\hline Regressão quadrática & - & - & - & $12,0569^{* * *}$ & - & - & - & - & - & - \\
\hline Desvios & 1 & $0,3946 *$ & $0,1557^{\mathrm{ns}}$ & $6,3951 *$ & - & & & & - & - \\
\hline $\mathrm{Li} /$ Prata & 3 & $0,3101^{\mathrm{ns}}$ & $17,6122^{\mathrm{ns}}$ & $2,9036^{\mathrm{ns}}$ & $8,8911^{\mathrm{ns}}$ & $3248,6896^{\mathrm{ns}}$ & $1950,6128^{\mathrm{ns}}$ & $970,2552^{n s}$ & $523,7264^{1 \mathrm{~ns}^{-}}$ & $16164 * *$ \\
\hline Regressão linear & 1 & $0,7836^{* * *}$ & - & - & - & - & - & - & - & $10008,5424^{\text {ns }}$ \\
\hline Regressão quadrática & - & - & - & - & - & - & - & - & - & $12040,3153^{\text {ns }}$ \\
\hline Desvios & 1 & $0,0625^{\mathrm{ns}}$ & - & $\ldots$ & $\ldots$ & - & - & - & - & $26442,1423 *$ \\
\hline Li / Thap Maeo & 3 & $0,0248^{\mathrm{ns}}$ & $13,1764^{\mathrm{ns}}$ & $2,3093^{\mathrm{ns}}$ & $2,0794^{\mathrm{ns}}$ & $1817,0959^{\text {ns }}$ & $1949,1368^{\text {ns }}$ & $1220,8387^{\mathrm{ns}}$ & $379,4351^{n s}$ & $6326,1523 * \cdots$ \\
\hline Regressão linear & 1 & - & - & - & - & - & - & - & - & $9999,5082^{\text {ns }}$ \\
\hline Regressão quadrática & - & - & - & - & - & - & - & - & - & $7446,9672^{\text {ns }}$ \\
\hline Desvios & 1 & & & & & & - & - & - & $1531,5246^{\mathrm{ns}}$ \\
\hline Resíduo c $(\mathrm{a}+\mathrm{b})$ & 99 & & & & & - & - & $\overline{-}$ & & - \\
\hline $\mathrm{CV}^{1}(\%)$ & - & 12,20 & 23,24 & 10,52 & 28,05 & 10,94 & 9,34 & 7,61 & 12,85 & 17,30 \\
\hline
\end{tabular}

*e**: valores significativos a $5 \%$ e $1 \%$ de probabilidade, respectivamente; ns: não-significativo. ${ }^{1}$ Coeficiente de variação.

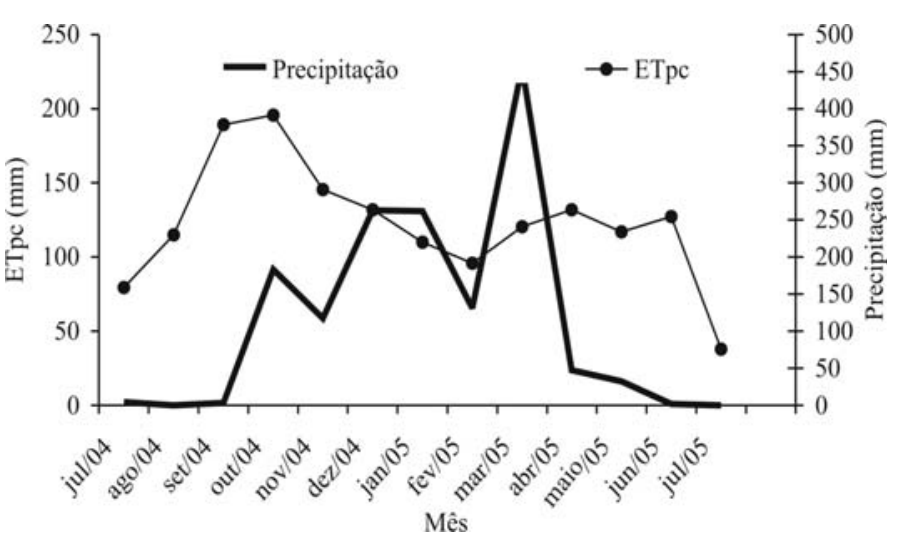

FIGURA 1 - Distribuição sazonal da evapotranspiração potencial da cultura e precipitação pluvial, no período do primeiro ciclo da cultura. Goiânia-GO. 2006.

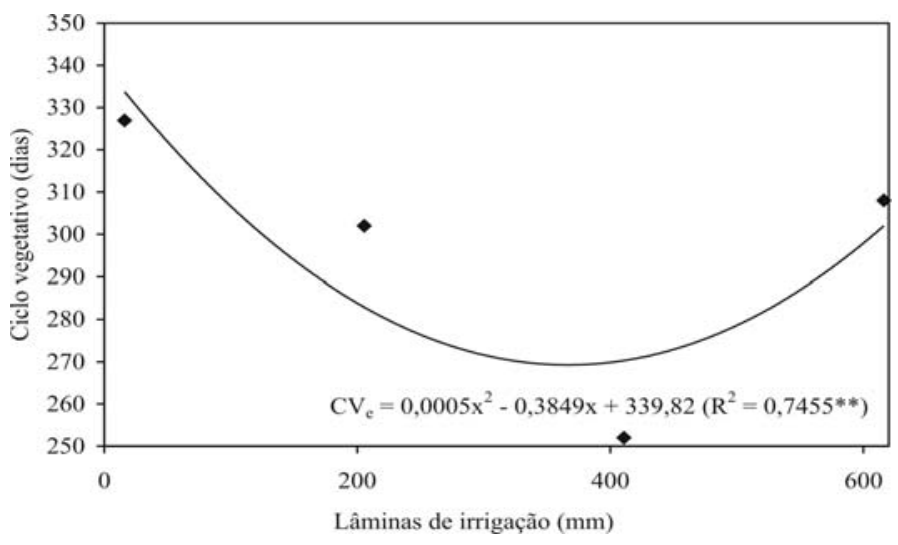

FIGURA 3 - Ciclo vegetativo $\left(\mathrm{CV}_{\mathrm{e}}\right)$ da cultivar falsa FHIA $18 \mathrm{em}$ função das lâminas de irrigação, na ocasião da colheita do primeiro ciclo. Goiânia-GO. 2006.

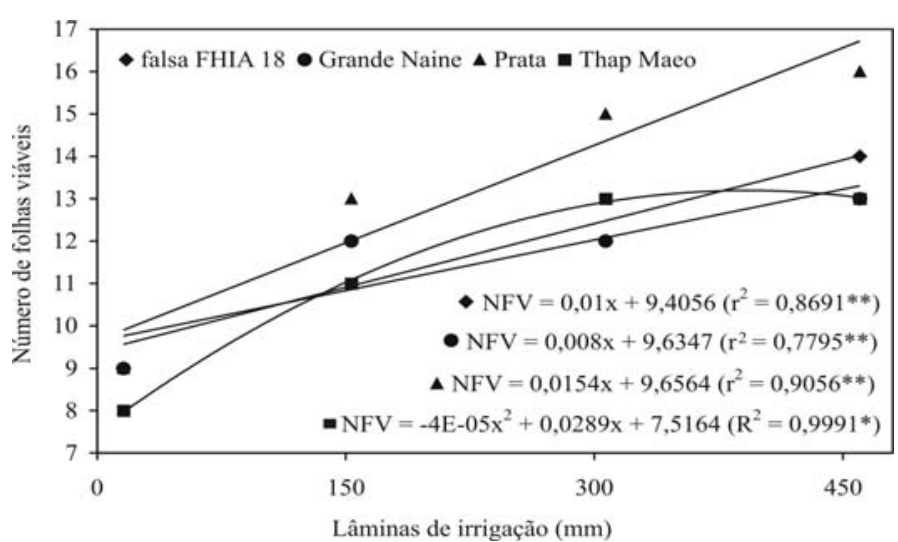

FIGURA 2 - Número de folhas viáveis (NFV) das cultivares falsa FHIA 18, Grande Naine, Prata e Thap Maeo em função das lâminas de irrigação, aos oito meses após o plantio. Goiânia-GO. 2006.

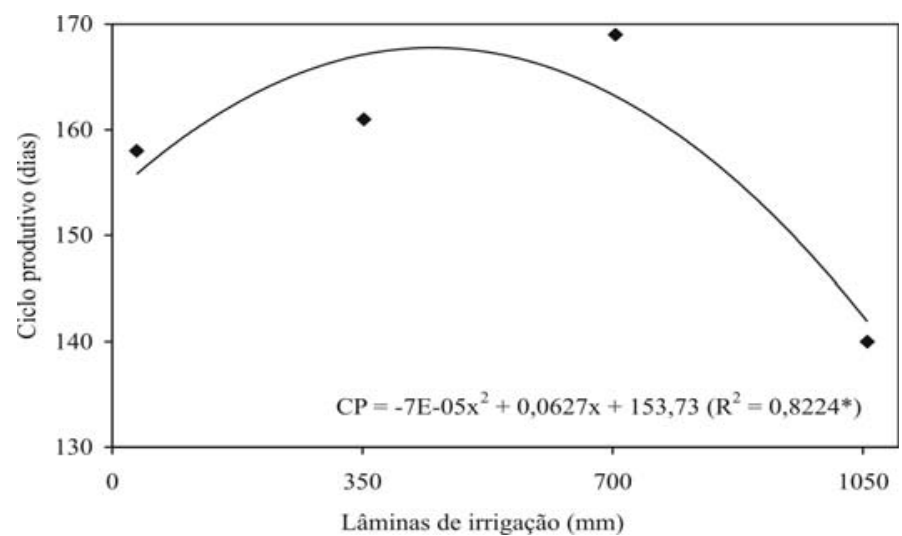

FIGURA 4 - Ciclo produtivo (CP) da cultivar falsa FHIA 18 em função das lâminas de irrigação, na ocasião da colheita do primeiro ciclo. Goiânia-GO. 2006. 


\section{CONCLUSÕES}

O crescimento e o desenvolvimento vegetativo das cultivares falsa FHIA 18, Grande Naine, Prata e Thap Maeo, nas condições do Cerrado, são influenciados positivamente com o uso da irrigação. $\mathrm{O}$ ciclo total das quatro cultivares diminui com o uso da irrigação.

\section{AGRADECIMENTOS}

Ao CNPq, pela concessão da Bolsa de Pesquisa, fator decisivo para a execução do trabalho.

\section{REFERÊNCIAS}

ALVES, E. J. A cultura da banana: aspectos técnicos, socioeconômicos e agroindústrias. 2. ed. Brasília: Embrapa, 1999. $585 \mathrm{p}$.

BORGES;A.L.;ALVES, E. J.; SILVA, S. O.; SOUZA,L. S.; MATOS, A. P.; FANCELLI, M.; OLIVEIRA, A. M. G.; CORDEIRO, Z. J. M.; SILVEIRA, J. R. S.; COSTA, D. C.; MEDINA, V. M.; OLIVEIRA, S. L.; SOUZA, J. S.; OLIVEIRA, R. P.; CARDOSO, C. E.L.; MATSUURA, F. C. A. U.; ALMEIDA, C. O. O cultivo da banana. Cruz das Almas: Embrapa, 1997. 109 p. (Circular Técnica, 27).

BRASIL. Ministério da Agricultura e Reforma Agrária. Secretaria Nacional de Irrigação. Departamento Nacional de Meteorologia. Normais climatológicas: 1961-1990, Brasília, 1992.84p.

COMISSÃO DE FERTILIDADE DE SOLOS DE GOIÁS. Recomendações de corretivos e fertilizantes para Goiás: $5^{\text {a }}$ aproximação. Goiânia: UFG/Emgopa, 1988. 101 p.

DONATO, S. L. R.; SILVA, S. O.; LUCCA FILHO, O. A.; LIMA, M. B.; DOMINGUES, H.; ALVES, J. S. Comportamento de variedades e híbridos de bananeira (Musa spp.), em dois ciclos de produção no sudoeste da Bahia. Revista Brasileira de Fruticultura, Jaboticabal, v. 28, n.1, p. 139-144, 2006.

DONATO, S. L. R.; SILVA, S. O.; PASSOS, A. R.; LIMA NETO, F. P.; LIMA, M. B. Avaliação de variedades e híbridos de bananeira sob irrigação. Revista Brasileira de Fruticultura, Jaboticabal, v. 25 , n.2, p. 348-351, 2003. Comunicação Científica

DOOREMBOS, J.; KASSAM, A. H. Efeito da água no rendimento das culturas. Campina Grande: UFPB, 1994. p. 306 (FAO. Irrigação e Drenagem, 33).

DOORENBOS, J.; PRUITT, W. O. Crop water requeriment. Rome: FAO, 1977. $144 \mathrm{p}$.
DOURADO NETO, D.; NIELSEN, D. R.; HOPMANS, J. W.; REICHARDT, K.; BACCHI, O. O. S. Software to model soil water retention curves (SWRC, version 2.0). Scientia Agrícola, Piracicaba, v. 57, n.1, p.191-196, 2000.

EMBRAPA - Centro Nacional de Pesquisa de Solos. Manual de métodos de análise de solo. Rio de Janeiro, 1997.212 p.

FANCELLI, M. Pragas. In: CORDEIRO, Z. J. M. (Org.). Banana. produção: aspectos técnicos. Brasília: Embrapa, 2000. v.1, cap. 12, p. $92-100$.

FREITAS JÚNIOR, E.; SILVA, E. M. Uso da centrífuga para determinação da curva de retenção de água no solo, em uma única operação. Pesquisa Agropecuária Brasileira, Brasília, v. 19, p. 1423-1428, nov. 1984.

GOEDERT, W. J. Região dos cerrados: potencial agrícola e política para seu desenvolvimento. Pesquisa Agropecuária Brasileira, Brasília, v. 24, n. 1, p. 1-17, 1989.

GONZAGA NETO, L.; SOARES, J. M.; CRISTO, A. S.; NASCIMENTO, T. Avaliação de cultivares de bananeira na região do submédio São Francisco. I. Primeiro ciclo de produção. Revista Brasileira de Fruticultura, Jaboticabal, v. 15, n. 1, p. 21-25, 1995.

LEITE, J. B. V.; SILVA, S. O.; ALVES, E. J.; LINS, R. D.; JESUS, O. $\mathrm{N}$. Caracteres da planta e do cacho de genótipos de bananeira, em quatro ciclos de produção, em Belmonte, Bahia. Revista Brasileira de Fruticultura, Jaboticabal, v. 25, n. 3, p. 443-447, 2003.

MOREIRA, R. S. Banana: teoria e prática de cultivo. 2. ed. Campinas: Fundação Cargill, 1999. 167 p. 1 CD-ROM.

MOREIRA, R. S. Banana: teoria e prática de cultivo. Campinas: Fundação Cargill, 1987. 335 p.

OLIVEIRA, S. L.; COELHO, E. F.; BORGES, A. L. Irrigação e fertiirrigação. In: CORDEIRO, Z. J. M. (Org.). Banana. produção: aspectos técnicos. Brasília: Embrapa, 2000, v. 1, cap. 9, p. 60-72.

PEREIRA, M. C. T. Crescimento e produção de primeiro ciclo da bananeira (Musa spp.) 'Prata Anã'(AAB) em sete espaçamentos, em Jaíba e Visconde do Rio Branco-MG. 1997. 56 f. Dissertação (Mestrado em Fitotecnia) - Universidade Federal de Viçosa, Viçosa, 1997.

SAS Institute. SAS Stat software: changes and enhancements through release 6.12. S Cary: SAS Institute, 1997. 1167 p.

SILVA, E. A.; BOLIANI, A. C.; CORRÊA, L. S. Avaliação de culturas de bananeira (Musa sp.) na região de Selvíria-MS. Revista Brasileira de Fruticultura, Jaboticabal, v. 28, n.1, p. 101-103, 2006. 
SILVA, L. B.; NASCIMENTO, J. L.; NAVES, R. V.; FERREIRA, P. H. Comportamento vegetativo de cultivares de banana sob diferentes lâminas de irrigação. Pesquisa Agropecuária Tropical, Goiânia, v. 34, n. 2, p. 93-98, 2004.

SILVA, L. B.; OLIVEIRA, L. F. C.; NASCIMENTO, J. L. Estimativa da demanda suplementar de irrigação da banana (Musa sp.) para diferentes épocas de plantio em Goiânia. Bioscience Journal, Uberlândia, v. 19, n. 2, p. 7-14, 2003.
SILVA, S. O.; FLORES, J. C. O.; LIMA NETO, F. P. Avaliação de cultivares e híbridos de bananeira em quatro ciclos de produção. Pesquisa Agropecuária Brasileira, Brasília, v. 37, n.11, p. 15671574, 2002.

VAN GENUCHTEN, M. A closed-form equation for predicting the hydraulic condutivit of unsatured soils. Soil Science American Journal, Madison, v. 44, p. 892 -898, 1980. 